\title{
A Model for Mobile Learning Integration in Higher Education Based on Students' Expectations
}

\author{
https://doi.org/10.3991/ijim.v14i11.13711 \\ Latinka Todoranova, Radka Nacheva ${ }^{(\bowtie)}$, Vladimir Sulov, \\ Bonimir Penchev \\ University of Economics-Varna, Varna, Bulgaria \\ r.nacheva@ue-varna.bg
}

\begin{abstract}
Mobile learning can be identified as the next stage in the development of e-learning. In this regard, the purpose of this paper is to propose a model for mobile learning integration in higher education which is based on analysis of students' expectations. To achieve this goal, a survey has been conducted among students enrolled in programs in the field of information and communication technologies. The analysis of the collected data shows that students have mobile devices, which they use not only for communication on social networks, but also for education. In addition, their expectations regarding mobile learning have been identified taking into account their study program and their previous experience with an e-learning platform.
\end{abstract}

Keywords - Mobile learning, higher education, m-learning success, students' expectations modeling, mobility

\section{Introduction}

Mobility can be identified as one of the basic needs of people, which makes their lives more fulfilling and which provides access to goods, services, social and economic relationships. It can be viewed from the following different perspectives:

- Physical - Regarding people with disabilities, their ability to move independently and their independence from a personal assistant, which can be achieved by using assistive technologies

- Geographic - Detecting the changes of the population of people in different areas of the world and their movement from one geographical location to another

- Economic - The ability of people and their families to improve their economic status

- Social - The movement of people between social classes and the change in their social status

- Technical - Implementation of human-computer interaction in various physical environments and movement of users with their mobile devices (laptops, tablets, smartphones, etc.) in environments with available or unavailable mobile connection

- Educational - The possibility for the learners to receive remote educational services regardless of their location. 
Mobility would not be possible without some of the significant innovations of the 20th century, the Internet and the mobile phones. "The Internet has become a monopolist of a significant portion of our daily life" [20]. In addition, there are some benefits for EU citizens when using mobile networks imposed by regulations and when operating within the Union. This in turn contributes to the increased use of high-speed Internet [27]. The analysis of the current development of the IT sector determines the need to formulate some novelties regarding information sharing [26]. It can be said that with the increased implementation of mobile connections, including licensed cellular IoT (around 9.5 billion by January 2020 [10]) and the increased use of smartphones (3.2 billion for 2019, which is 0.7 billion more than 4 years ago [7]) the need for flexibility in the use of educational services in line with the migration of people in today's dynamic world is growing exponentially. Educational services are changing according to the new circumstances, becoming more flexible and learner-oriented. Over 194 billion are the registered mobile app downloads worldwide [8], of which approximately $46 \%$ are used to access educational information / services [9].

Taking into account the above mentioned, we can claim that mobile learning is one of the contemporary natural extensions of e-learning. In this regard, the purpose of this paper is to propose a model for mobile learning integration in higher education which is based on analysis of students' expectations. To achieve this goal, a survey has been conducted among students enrolled in study programs in the field of information and communication technologies.

\section{Frameworks for M-Learning Success}

The integration of information and communication technologies into the educational process, the development of e-learning and its gradual transformation into mobile learning are actively researched topics in the scientific literature. The model widely used when studying the degree of user perception of information technology is the Unified Theory of Acceptance and Use of Technology (UTAUT) [2], proposed in 2003. The authors of this model have found out that the main factors influencing the adoption of information technology are:

- Performance expectancy

- Effort expectancy

- Social influence

- Facilitating conditions.

The development of mobile technologies leads to research process connected with the main factors influencing the adoption of mobile technologies. In the field of mobile learning, Cochrane [3] has identified the following elements that are of great importance for its successful implementation:

- Integration of technology and pedagogical approaches

- Regular feedback from learners to educators

- Specific capabilities of the used mobile devices 
- Functionality of the software.

Two years later, Elmorshidy [4] has offered a theoretical framework for the success of mobile learning (see Figure 1).

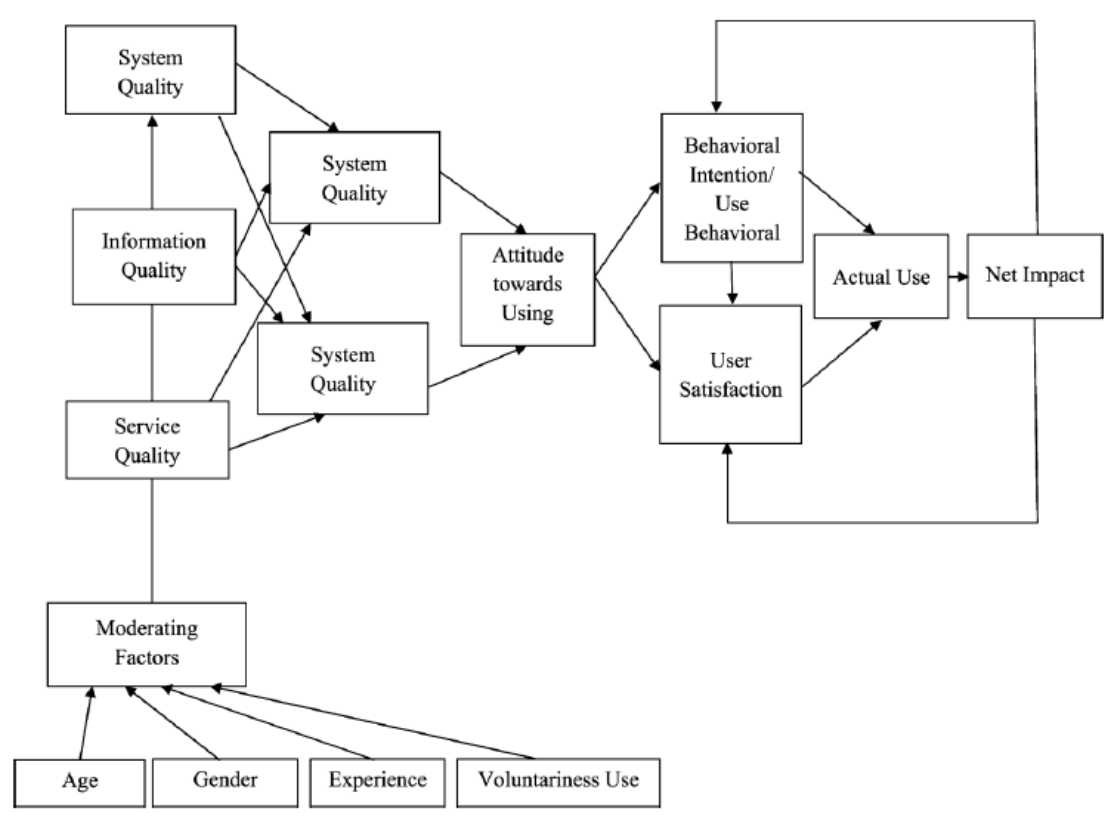

Fig. 1. Theoretical Framework for Mobile Learning Success [4]

The proposed framework addresses the main elements that influence the success of any information system. The first mentioned elements are the quality of the system, the quality of information and the quality of services. On the other hand, the authors have taken into account user satisfaction and the ease of system use. These factors prove to be decisive for users when changing their behavior (habits) and starting to use actively a certain information system. Another study of the factors influencing the success of mobile learning [5] cites accessibility, interface design and security features as the determinants for the wider and more active use of mobile learning applications. Bidin and Ziden [6] have also examined the factors that influence educators' and learners' motivation to use mobile learning applications. The authors have classified these factors into three main categories:

- Features of the devices

- User expectations

- Pedagogical advantage.

In addition, it is important to pay attention to the factors that affect the quality of educational services. There is an approved multi-dimensional research instrument which is used for capturing users' expectations and perceptions about service quality - 
SERVQUAL, developed by Parasuraman, Ziethaml and Berry in 1988. SERVQUAL is a questionnaire that consists of 22 expectation items and 22 perception items, organized into five dimensions [22]. This instrument is useful for tracking quality change trends. The dimensions of SERVQUAL are:

- Reliability (5 items) - Refers to the reliable and accurate provision of a service

- Assurance (4 items) - Whether the employees have the necessary knowledge and whether they manage to inspire confidence when providing the service;

- Tangibles (4 items) - Refers to the physical facilities, equipment and communication materials that are used;

- Empathy (5 items) - Refers to the provision of careful and individual attention to the user;

- Responsiveness (4 items) - The willingness to help users and the provision of fast service.

In 1994, Cronin and Taylor have developed a modification of SERVQUAL SERVPERF, which criticized Parasuraman, Ziethaml and Berry's service quality model. SERVPERF uses the same dimensions but reduces the questions to 22, which measure quality as a ratio rather than satisfaction [23].

SERVQUAL and SERVPERF can be implemented in a variety of spheres, including education, by adapting to the needs of an organization and by applying them in conjunction with other tools used to measure the quality of services.

Stecyk [18] has proposed a model of educational services quality in higher education (Figure 2) that could be considered appropriate in the context of mobile learning implementation.

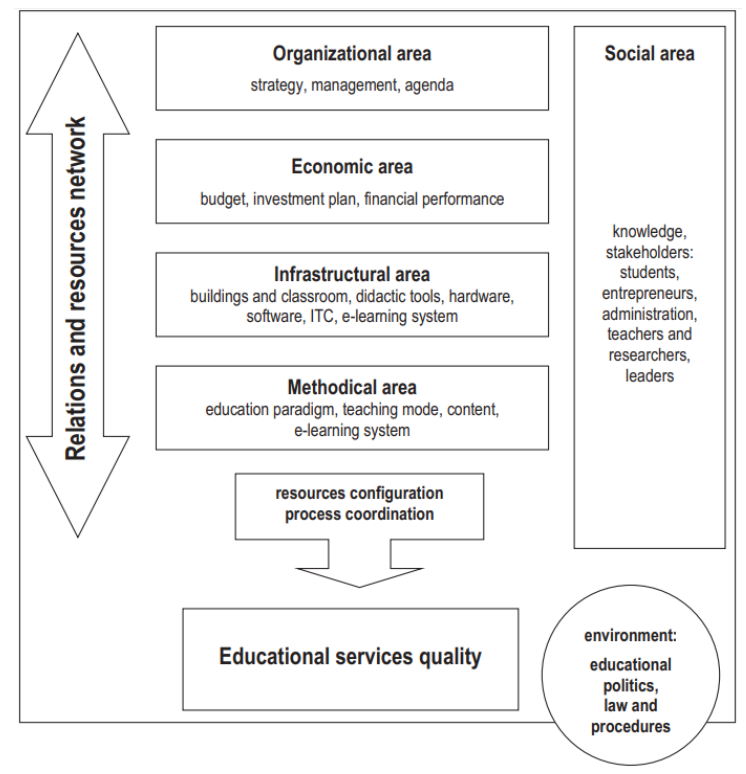

Fig. 2. Schematic diagram of the educational services quality in higher education [18] 
The model takes into account several areas with impact on educational services quality:

- Organizational (strategy, management, agenda)

- Economic (budget, investment plan, financial performance)

- Infrastructural (buildings and classroom, didactic tools, hardware, software, ITC, elearning system)

- Methodical (education paradigm, teaching mode, content, e-learning system)

- Social (knowledge, stakeholders).

In early 2019, UNESCO has published research results of the best practices for the implementation of mobile learning [1]. The successful mobile learning initiatives are from the following countries: Uruguay [11], Korea [13], Spain [12], [16], Croatia [15], China [14] and Brazil [17]. The main goal of the project is to present successful approaches for planning and mobile learning integration. It involves initiatives initiated by the government as well as by the educational institutions themselves.

The cited studies are the main motivation for the authors of the current research paper to develop a model for mobile learning integration in higher education. However, in order to be effective and efficient, the future initiatives in the field of mobile learning must follow the good practices that are proven in a number of other projects. These practices generally include the following guidelines:

- To improve the digital skills of educators and learners

- To motivate educators and learners to work in a new environment with new resources

- To equip the classrooms with mobile devices and up-to-date technologies, supporting the educational process

- To develop content management platforms for education

- To develop mobile learning applications

- To create and implement standards for electronic resources

- To ensure protection of personal data and copyright.

Based on the studies presented, we can claim that the main factor for the success of mobile learning is the user with their expectations. The education must be adequate for today's "digital" students, whose social communication and learning style is very different from that of the previous generations. In this context, the present paper offers a model for mobile learning integration into higher education, based on the analysis of students' expectations. The research is aimed at students' mobile devices, mobile applications they work with and the learning resources they use. For this purpose, a survey was conducted among bachelor's and master's students enrolled in majors in the field of information and communication technologies.

\section{$3 \quad$ Study of Students' Attitude Towards Mobile Learning}

In order to examine students' attitude towards mobile learning, a questionnaire has been conducted. It includes the following groups of questions: audience profile (age, 
study program, year of study); experience in e-learning at the University of Economics - Varna; attitude towards mobile learning. It is necessary to analyze the data from the following perspective: "data inspecting and transforming process for the purpose of making conclusions and obtaining useful information to help make a decision about disclosed forecasts" [19].

The questionnaire has been distributed among 180 students and 109 of the received responses are valid. Approximately $93 \%$ of the participants are from bachelor's major, while the rest are from master's major. $71 \%$ of them are between 19 and 21 years old. As representatives of the digital generation, each participant owns a smartphone, $89 \%$ of them own a laptop and $28.4 \%$ of them - a tablet. Over $75 \%$ of the researched students have experience with Google's Android mobile operating system and over $31 \%$ use Apple iOS. 94.5\% say they use high-speed Internet, which indicates their need for continued connectivity and constant use of online services.

Students from the University of Economics - Varna use the e-learning platform available at e-learn.ue-varna.bg. It is based on the Moodle platform and is used by all departments in the university. As students in the field of information and communication technology, respondents use the platform in each of the courses they are enrolled, which means that they have experience and expectations for e-learning. Approximately $89 \%$ of the survey participants use the e-learning platform via a mobile device.

The materials that the lecturers share on the e-learning platform are most often in the form of PDF / DOC files; video / audio content; Power Point / Prezi presentations; text files / pages.

$76.2 \%$ of the participants report submitting their semester assignments through the platform, and approximately $70 \%$ of them also use it to take semester or exam tests.

Concerning their attitude towards mobile learning, $73.4 \%$ of the respondents say that they are using mobile applications for learning purposes, and $94.9 \%$ - that they are going to use such mobile applications.

$56.3 \%$ of the survey participants indicate that they use learning resources through their mobile devices. These resources are not only related to the study programs that are part of the educational process at the university, but are also related to other courses. $31.1 \%$ indicate that they only use study resources through their mobile devices that are strongly related to the courses studied at the university and $12.6 \%$ use additional materials (unrelated to the courses studied).

Participants in the survey share they have experience with the following types of mobile learning applications:

- Mobile learning applications developed for the purposes of a particular program / course / university $-65.6 \%$

- Content management platforms such as Moodle, Blackboard, eLearn - 64.6\%

- Platforms providing various courses such as Coursera, edX, Udemy, Lynda $-16.7 \%$.

The platforms the students point out are: Udemy, Moodle, Ucha.se, Duolingo, Memrise, SoloLearn, Coursera, Quizlet, freeCodeCamp, Kahoot, Khan Academy.

Guided by the presumption of learning mobility, $50.9 \%$ use similar mobile applications when they are on the move and regardless of their physical location. $72.2 \%$ 
responded that they use these applications at home, $47.2 \%$ - to study at the university and $11.1 \%$ - to study at their workplace.

Regarding the frequency of using mobile learning applications, $70 \%$ of the students respond that they use them between 1 and 5 times a day, and 13\% even more often between 5 and 10 times a day.

Of interest for this survey is the students' opinion on the limitations that users have when using mobile applications, including m-learning applications. According to the questionnaire they are: screen size $(47 \%)$; data entry methods $(35 \%)$; battery capacity $(54 \%)$; amount of mobile data available (33\%); internet connection speed (31\%); storage space for the resources (24\%); inconvenience of the user interface (9\%). One of the problems that participants share when dealing with the content of these applications is that most of the learning materials are theoretical. They prefer more practical examples to demonstrate the application of theory in a given subject area.

Based on the research of students' opinions on mobile learning integration in higher education it can be said that they have experience with mobile learning applications. This in turn means that they also have expectations for the functionality and convenience of these applications. Students have already experienced and expectations for elearning platforms and for the ways of providing educational content - in the form of documents, presentations or video / audio files.

\section{A Model for Mobile Learning Integration in Higher Education}

Considering the researched frameworks for e-learning success and the survey results for the expectations of students, we can outline the following guidelines to consider when developing a model for mobile learning integration in higher education:

- Provision of user experience that meets the expectations of the digital generation

- Management of learning materials of different types

- Integration with the existing e-learning systems in the educational institution [25] as they are the key to the existence of organizations, and their features should be well known to the administrators [24]

- Quality assurance - based on the following research papers [21], [28], [29], we can point out quality as a main problem of software products, which directly affects the user experience

- Provision of data regulation mechanisms, including alignment with international legal frameworks, standards and frameworks for secure data exchange.

Taking into account the aforementioned guidelines, we propose the complex model, presented in Figure 3. 


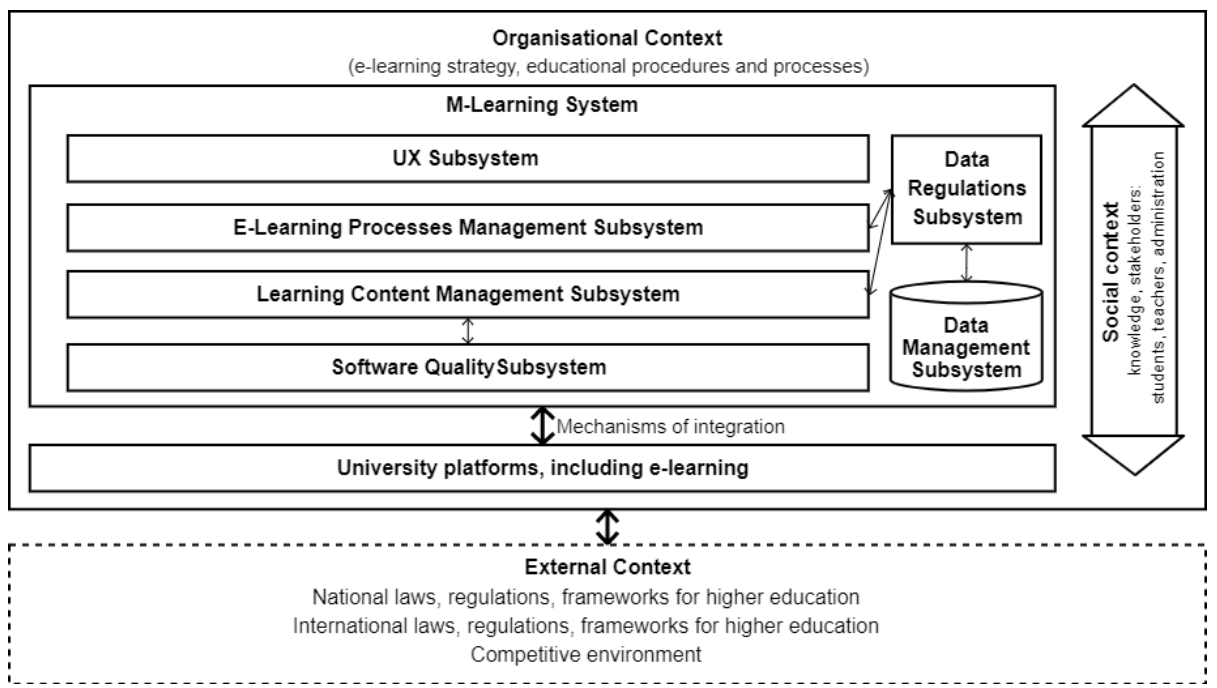

Fig. 3. A Model for Mobile Learning Integration in Higher Education Source: Own Elaboration

Similar to [18], in the model attention is paid to the peculiarities of the social context, which is strictly specific to each social unit that is distinguished within the organizational context. As stated in [30], the human social environment is a complex concept, denoting the totality of physical environment, social connections and cultural environment within which groups of people function and interact. According to the same survey, the social environment consists of: infrastructure; industrial and occupational structure; labor markets; social and economic processes; wealth; social, human, and health services; government; race relations; social inequality; cultural practices; the arts; religious institutions and practices; and beliefs about place and community.

From one point of view it can be claimed that studying the interaction between social units in a specific organizational context is important for building environment-friendly software systems and in particular e-learning systems. In this way, the specific needs of stakeholders (trainees, teachers, administration) should be addressed.

On the other hand, the mobile learning integration is also dependent on the organizational context, and in particular on whether there is a strategy adopted for the digitalization of the administrative and educational process at the university. If an organization takes the "digital first" approach:

- Paper-based activities should be kept to a minimum

- The administrative obligations of lecturers and students will be reduced due to the automation of most activities within the organization, which in turn will increase the engagement of both parties to the learning process

- The communication between students, lecturers and administration will be improved and the needed feedback will be obtained in various cases

- Students' attention will be drawn to the adoption of new digital skills, which will prepare them better for the requirements of Industry 4.0, etc. 
When introducing mobile learning at a university, the software system cannot exist on its own, but it must integrate successfully with the existing systems. For example, the connectivity to the university information system provides faster access to the student's status and also means for updating it after passing semester tests.

There are several essential components of a mobile learning system:

- User experience subsystem - It is used to influence user satisfaction when working with the system. It includes the presentation model and logic of the system. They both define the logical behavior and structure of the application in a way that is independent of any specific implementation of the user interface. The presentation model encapsulates the data transmitted by the e-learning processes management subsystem and thus presents it in an accessible and reproducible format for the user.

- E-learning processes management subsystem - Contains all components of the system that implement its business logic. It focuses on the recovery, processing, transformation and management of software product data through the application of business rules and policies, including data compatibility and validity [31].

- Learning content management subsystem - The educational content is divided into educational objects, which can be stored in different formats - presentations, documents, video and audio, tests, questionnaires, pages, forums, etc.

- Software quality subsystem - Provides a set of procedures and functions for quality control of the mobile learning system, including data integrity, data compliance and other activities.

- Data regulations subsystem - Groups all system components that combine the necessary logic to access the data warehouses. In the context of the General Data Protection Regulation (GDPR), the data protection regulation imposed on the educational institution is taken into account.

- Data management subsystem - Refers to the methods of storing, recovering and deleting data, maintaining a metadata dictionary, maintaining transactions and other functionality provided by database management systems.

\section{Conclusion}

In summary, mobile learning integration in higher education depends on the stakeholders' attitudes towards changing the learning model. On the one hand, today's "digital" students have mobile devices, high-speed Internet access and they use different learning resources on the devices they own. On the other hand, the university policy should be targeted at implementing the "digital first" approach in order to modernize the teaching approaches and the provided learning resources. In this regard, the positive effects of mobile learning integration for the educators are mainly related to improving communication with learners, increasing their engagement with the learning process and meeting their needs for learning on the move.

The proposed model of mobile learning integration in higher education recognizes the importance of the organizational context and interaction of the social units that form within its framework. Also, the organizational context is directly dependent on the restrictions imposed by the external environment, such as national and international legal 
frameworks, as well as by the competitive environment (competition between universities for quality students).

\section{References}

[1] UNESCO. Best practices in mobile learning: 7 innovative case studies. [Online]. Available: https://en.unesco.org/news/best-practices-mobile-learning-7-innovative-case-studies. [Accessed 10/01/2020].

[2] Venkatesh, V., Morris, M., Davis, G., Davis, F. (2003). User Acceptance of Information Technology: Toward a Unified View. MIS Quarterly, 27(3): 425-478. https://doi.org/10. 2307/30036540.

[3] Cochrane, T. (2010). Exploring mobile learning success factors. ALT-J, Research in Learning Technology, 18(2): 133-148.

[4] Elmorshidy, A. Mobile Learning - A New Success Model. The Journal of Global Business Management 18, Volume 8, Number 2, August 2012.

[5] Alzu'Bi, S., Hassan, S. (2016). Factor Affecting the Success of Mobile Learning Implementation: A Study of Jordanian Universities. Asian Journal ot Information Technology, 15(1): 113-121.

[6] Bidin, S., Ziden, A. (2013) Adoption and application of mobile learning in the education industry. 6th International Conference on University Learning and Teaching (InCULT 2012), Procedia - Social and Behavioral Sciences, 90: 720 - 729. https://doi.org/10.1016/ j.sbspro.2013.07.145

[7] Statista.com. Number of smartphone users worldwide from 2016 to 2021 (in billions). Available: https://www.statista.com/statistics/330695/number-of-smartphone-users-worldwide/. [Accessed 10/01/2020].

[8] Statista.com. Number of mobile app downloads worldwide from 2016 to 2018 (in billions). Available: https://www.statista.com/statistics/271644/worldwide-free-and-paid-mobileapp-store-downloads/. [Accessed 10/01/2020].

[9] GSMA. The Mobile Economy 2019. Available: https://www.gsmaintelligence.com/research/?file=b9a6e6202ee1d5f787cfebb95d3639c5\&download. [Accessed 10/01/2020].

[10] GSMA Intelligence. "Definitive data and analysis for the mobile industry". Available: https://www.gsmaintelligence.com/. [Accessed 10/01/2020].

[11] Romaní, C., Vargas, C. (2018). Enhancing social inclusion through innovative mobile learning in Uruguay: Case study by the UNESCO-Fazheng project on best practices in mobile learning. UNESCO.

[12] Hinostroza, J. (2018). Mobile Learning as a long-term institutional innovation strategy in Spain: Case study by the UNESCO-Fazheng project on best practices in mobile learning. UNESCO.

[13] Lim, C., Kye, B. (2019). Classroom revolution through SMART education in the Republic of Korea: Case study by the UNESCO-Fazheng project on best practices in mobile learning. UNESCO.

[14] Yu, Y., Wang, S., Haagen, L. (2019). Mobile learning as a catalyst to global citizenship education in China: Case study by the UNESCO-Fazheng project on best practices in mobile learning. UNESCO.

[15] Smoljo, A., Korda, A. (2019). Establishing a system for developing digitally mature schools in Croatia: Case study by the UNESCO-Fazheng project on best practices in mobile learning. UNESCO. 
[16] Forn, A., Castro, J., Camacho, M. (2019). mSchools: Transforming the education landscape in Catalonia (Spain) through a systemic and inclusive mobile learning programme: Case study by the UNESCO-Fazheng project on best practices in mobile learning. UNESCO.

[17] Barbosa, A., Rovai, A., Gonçalves, G. (2019). Empowering students to become agents of social transformation through mobile learning in Brazil: Case study by the UNESCOFazheng project on best practices in mobile learning. UNESCO.

[18] Stecyk, A. (2017). Increasing the Level of Educational Services Quality in Higher Education. European Journal of Service Management, 23(3): 71-78. https://doi.org/10.18276/ ejsm.2017.23-09

[19] Sulova, S. (2019). Models for Web Applications Data Analysis. Proceedings of 20th International Conference on Computer Systems and Technologies, pp. 246-250.

[20] Bankov, B. (2019). Software Evaluation of PHP MVC Web Applications. Conference Proceedings of 19 International Multidisciplinary Scientific Geoconference SGEM 2019, 19(2.1): 603 - 610. https://doi.org/10.5593/sgem2019/2.1/s07.079

[21] Stecyk, A. (2018). The Analytic Hierarchy Process AHP for Business Intelligence System Evaluation. European Journal of Service Management, 28(2): 439-446. https://doi.org/10. 18276/ejsm.2018.28/2-52

[22] Parasuraman, A., Ziethaml, V., Berry, L. L. (1988). SERVQUAL: A Multiple- Item Scale for Measuring Consumer Perceptions of Service Quality. Journal of Retailing, 64(1): 12-40.

[23] Cronin, J., Taylor, S. (1994). SERVPERF versus SERVQUAL: Reconciling PerformanceBased and Perceptions-Minus-Expectations Measurement of Service Quality. Journal of Marketing, 58(1): 125-131. https://doi.org/10.1177/002224299405800110

[24] Kuyumdzhiev, I. (2019). Comparing Backup and Restore Eficiency in MySQL, MS SQL Server and MongoDB. Conference Proceedings of 19 International Multidisciplinary Scientific Geoconference SGEM 2019, 19(2.1): 167 - 174. https://doi.org/10.5593/sgem $\underline{2019 / 2.1 / \mathrm{s} 07.022}$

[25] Kostadinova, I., Toshev, R., Petrov, P., Aleksiev, K., Getova, I. (2018). Temporal Analysis of the Pedagogical Adoptions use and Application of the Augmented and Virtual Reality Technologies in Technical Subject Areas. Proceedings of 11th Annual International Conference of Education, Research and Innovation, ICERI2018, pp. 4387 - 4393. https://doi. org/10.21125/iceri.2018.1991

[26] Vasilev, J., Stoyanova, M. (2019). Information Sharing with Upstream Partners of Supply Chains. Conference Proceedings of 19 International Multidisciplinary Scientific Geoconference SGEM 2019, 19(2.1): 329 - 336. https://doi.org/10.5593/sgem2019/2.1/s07.043

[27] Czaplewski, M. (2018). Creating a Single Digital Market for Telecommunications Services as a Challenge for the European Union. Gospodarka Narodowa, 293(1): 159-181. (in Polish). https://doi.org/10.33119/gn/100573

[28] Eskenazi, A. (2007). Evaluation and management of the software quality. Journal of the Bulgarian Academy of Sciences, 6: 42-47. (in Bulgarian)

[29] Chen, C. et. al. (2019). Exploring the Dependency Relationships between Software Qualities. 2019 IEEE 19th International Conference on Software Quality, Reliability and Security Companion (QRS-C), pp. 105-108. https://doi.org/10.1109/qrs-c.2019.00032

[30] Barnett E, Casper M. (2001). A definition of "social environment". American Journal of Public Health, 91(3): 465. doi:10.2105/ajph.91.3.465a.

[31] Microsoft. Business Layer Guidelines. Available: https://docs.microsoft.com/en-us/previous-versions/msp-n-p/ee658103(v=pandp.10)?redirectedfrom=MSDN.[Accessed 20/01/20 20]. 


\section{$7 \quad$ Authors}

Latinka Todoranova is a Chief Assistant Professor at the Department of Computer Science of the Faculty of Informatics at the University of Economics - Varna. She acquired her PhD degree in the same university in 2015. Her interests include mobile learning, business intelligence and programming. Email: todoranova@ue-varna.bg.

Radka Nacheva is a Chief Assistant Professor at the Department of Computer Science of the Faculty of Informatics at the University of Economics - Varna. She acquired her $\mathrm{PhD}$ degree in the same university in 2017. Her research interests are in HumanComputer Interaction, Cognitive Science and Software Accessibility. Email: r.nacheva@ue-varna.bg.

Vladimir Sulov is a Professor at the Department of Computer Science of the Faculty of Informatics at the University of Economics - Varna. His interests include algorithms, programming, web applications. Email: vsulov@ue-varna.bg.

Bonimir Penchev is a Chief Assistant Professor at the Department of Computer Science of the Faculty of Informatics at the University of Economics - Varna. He acquired his PhD degree in Bulgarian Academy of Sciences in 2016. His interests include mobile technology, security, programming and computer hardware. Email: b.penchev@ue-varna.bg.

Article submitted 2020-02-11. Resubmitted 2020-03-17. Final acceptance 2020-03-29. Final version published as submitted by the authors. 